\title{
AVALIAÇÃO DE MÉTODOS DE EXTRAÇÃO DE SILÍCIO EM SOLOS CULTIVADOS COM ARROZ DE SEQUEIRO(1)
}

\author{
G. H. KORNDÖRFER ${ }^{(2)}$, N. M. COELHO(3), \\ G. H. SNYDE $\mathbf{R}^{(4)} \&$ C. T. MIZUTANI ${ }^{(5)}$
}

\begin{abstract}
RESUMO
Este trabalho teve como objetivo avaliar a eficiência de quatro métodos de extração (ácido acético 0,5 mol L-1, tampão pH 4,0, cloreto de cálcio 0,0025 mol L-1e água) em estimar a disponibilidade de silício (Si) no solo para plantas de arroz de sequeiro cultivadas em casa de vegetação. Quatro solos, correspondentes às classes: Latossolo Vermelho-Escuro álico (LEa), Latossolo Vermelho-Amarelo álico (LVa), Latossolo Roxo distrófico (LRd) e Areia Quartzosa álica (AQa), todos da região do Triângulo Mineiro e ainda não cultivados foram utilizados no estudo. Cinco níveis de Si foram estabelecidos em cada um dos solos. Plantas de arroz foram cultivadas em vasos até a maturação. Como resultado deste trabalho, concluiu-se que $o$ ácido acético $0,5 \mathrm{~mol} \mathrm{~L}^{-1}$ foi o método que apresentou a melhor estimativa do Si disponível no solo para o arroz de sequeiro. $\mathrm{O}$ silício da parte aérea do arroz revelou alta correlação com o Si extraível pelo método ácido acético.
\end{abstract}

Termos de indexação: disponi bilidade, extratores químicos, Latossolos, silicato de cálcio.

(1) Recebido para publicação em março e aprovado em outubro de 1998.

(2) Professor Titular do Departamento de Agronomia, Universidade Federal de Uberlândia - UFU. Caixa Postal 593, CEP 38400-902 Uberlândia (MG). Bolsista do CNPq.

(3) Professora Adjunta do Departamento de Química, UFU. Uberlândia (MG).

(4) Distinguish Professor. University of Florida. Everglades Research \& Education Center. P.O. Box: 8003, Belle Glade, FI 33430, USA.

(5) Departamento de Química, Universidade Federal de Uberlândia. 


\title{
SUMMARY: EVALUATION OF SOIL EXTRACTANTS FOR SILICON AVAILABILITY IN UPLAND RICE
}

\begin{abstract}
Thesuitability of four extraction methods (acetic acid $0.5 \mathrm{~mol} \mathrm{~L}^{-1}$, buffer $\mathrm{pH} 4.0$, cal cium chloride $0.0025 \mathrm{~mol} \mathrm{~L}^{-1}$ and water) for estimating the amount of available Si in soil for upland rice was determined. Four soil types corresponding to the following classes were used:Typic Acrustox - isohyperthermic (LEa), Typi cAcrustox - isohyperthermic (LVa), Rhodic Acrustox - isohyperthermic ( $L R d$ ) and Ustoxic Quartzipsammentic - isohyperthermic (AQa), all of them from the Triângul o Mineiro region in Minas Gerais, Brazil. FiveSi levels were created in each of the soils by applying calcium silicate U pland ricewas grown to maturity in pots of each soil in greenhouse Among the extractants studied, the acetic acid $0.5 \mathrm{~mol} \mathrm{~L}^{-1}$ gavethebest estimatefor theavailableSi in soil. Thesilicon content found in theleaves was highly correl ated with extractable Si by the acetic acid $0.5 \mathrm{~mol} \mathrm{~L}^{-1}$ method.
\end{abstract}

Index terms: availability, Latosol, extractant, calcium silicate

\section{NTRODUÇÃO}

A análise de silício (Si) no solo não é feita pelos laboratórios de rotina noBrasil. A falta decalibração demétodos para Si tem dificultado aos pesquisadores estudar o papel desse elemento na nutrição das plantas. Sabe-se que o Si é um dos elementos mais abundantes encontrados na crosta terrestre eque a adubação com Si pode resultar em aumento na produtividade de várias culturas como é o caso do arroz, cana-de-açúcar e outras (Fox et al., 1967; Datnoff et al., 1991; Anderson et al., 1991). Esses autores têm relacionado a presença do Si na planta com resistência a pragas edoenças, mai or capacidade fotossintética (as folhas ficam mais eretas e a incidência deluz émaior) etolerância à fal ta deágua. Apesar disso, o Si não é considerado um nutriente essencial para as plantas.

Sendo oSi um el emento importante para al gumas espécies de plantas, é essencial o desenvolvimento de métodos de análise que possam estimar sua disponibilidade no solo. Nesse sentido, Nonaka \& Takahashi (1990) desenvolveram um método baseado na incubação do solo por duas semanas a $40^{\circ} \mathrm{C}$ e usando a água como extrator. A pós o período de incubação, o Si é analisado no sobrenadante.

$\mathrm{O}$ método de extração com $\mathrm{CaCl}_{2} \quad 0,01 \mathrm{~mol} \mathrm{~L}^{-1}$ é comumenteusado numa série de determinações, tais como cátions trocáveis e pH. Esse extrator tem a propriedade de simular a força iônica da solução e o $\mathrm{pH}$, entretanto, o processo químico envol vido é pouco estudado e pouco tem sido feito para entender a cinética de liberação dos cátions da fase sólida para a solução. Segundo Gibson (1994), a extração do Si com $\mathrm{CaCl}_{2} \quad 0,01 \mathrm{~mol} \mathrm{~L}^{-1}$ é intensa nas primeiras 24 horas de contato com o solo. A partir daí, a extração éessencial mentelinear com otempo. Nesse caso, o autor acredita quea primeira hora deextração deva refletir melhor a disponibilidade do Si para as plantas; entretanto, reconhece que a quantidade de Si é muito dependente do tempo de extração.

Pesquisadores japoneses são os que mais apresentam trabalhos relacionados com 0 desenvolvimento de métodos para análise de Si no solo. Para Nonaka \& Takahashi (1990), ao contrário do que foi observado por Shiue (1964), tampão de acetato a pH 4,0 é muito forte para estimar a disponibilidade de $\mathrm{Si}$, mas é dos EUA que vem um dos métodos de extração mais utilizados para Si no solo. Snyder (1991) demonstrou que o ácido acético $0,5 \mathrm{~mol}^{-1}$, além de prático, tem sido bastante eficiente em identificar solos deficientes em Si. Segundo o autor, esse extrator vai muito bem tanto nos solos orgâni cos como nos solos arenosos.

A determinação do Si extraível, além da sua importância para identificação de solos deficientes em Si, tem interesse no estudo de fenômenos pedogenéticos, considerando quea remoção da sílica do perfil do solo é um dos principais aspectos do intemperismo químico nos trópicos.

Este trabalho teve como objetivo avaliar a eficiência de quatro métodos de extração em quantificar o Si disponível no solo para plantas de arroz de sequeiro cultivadas em casa de vegetação.

\section{MATERIAL E MÉTODOS}

\section{Estudo do Si acumulado na planta}

Este estudo foi realizado em casa de vegetação, utilizando amostras da camada de $0-20 \mathrm{~cm}$ de profundidade de quatro solos, correspondentes às classes: Latossolo Vermelho-Escuro álico (LEa), 
Latossolo Vermel ho-Amarelo álico (LVa), Latossolo Roxo distrófico (LRd) eAreia Quartzosa álica (AQa), todos da região do Triângulo Mineiro (EMBRAPA, 1982) e deáreas ainda não cultivadas. Os resultados das análises químicas, textural e mineralógica, encontram-se nos quadros 1 e 2 , respectivamente. Cinco níveis deSi foram estabel ecidos em cada solo. O silicato de cálcio (wollastonita - $\mathrm{CaSiO}_{3}$ ) foi fornecido pela empresa I piranga Química de São Paulo (produto comercial - Vansil, EW-20). O silicato $\left(51,9 \%\right.$ de $\left.\mathrm{SiO}_{2}\right)$ foi incorporado ao sol o 30 dias antes do plantio nas dosagens equivalentes a: 0 (testemunha), 120, 240, 480 e $960 \mathrm{~kg}$ ha-1 de Si, em vasos que continham $8 \mathrm{~kg}$ de terra seca ao ar. $\mathrm{O}$ cultivar de arroz plantado foi o IAC-165.

A análise de Si nas plantas de arroz foi feita segundo o método descrito por Elliott \& Snyder (1991) adaptado. Pesou-se 0,1000 g da amostra (tecido foliar) e colocou-se em tubo de plástico. A seguir, foram acrescentados $2 \mathrm{~mL}$ de $\mathrm{H}_{2} \mathrm{O}_{2}$ (30 ou $50 \%$ ) mais $3 \mathrm{~mL}$ de $\mathrm{NaOH}$ (1:1). Depois de agitados, os tubos foram imediatamente colocados na autoclave por um período de $1 \mathrm{~h}$ a $123^{\circ} \mathrm{C}$ e $1,5 \mathrm{~atm}$. de pressão. Uma alíquota do material digerido foi misturado com $2 \mathrm{~mL}$ de molibdato de amônio 1:5 $\left[\left(\mathrm{NH}_{4}\right)_{6} \mathrm{Mo}_{7} \mathrm{O}_{24} \cdot 4 \mathrm{H}_{2} \mathrm{O}\right.$ : água destilada] para a formação do complexo amarelo ácido sílico-molíbdico $\left[\mathrm{H}_{4}\left(\mathrm{SiM} \mathrm{O}_{12} \mathrm{O}_{40}\right)\right]$. A formação do complexo ácido sílico-molíbdico é máxima entre $\mathrm{pH} 1,0$ e 2,0. Para baixar o pH das amostras, quantidades proporcionais ao volume da alíquota foram adicionadas de $\mathrm{HCl}(50 \%)$. O ácido 1-amino-2-naftol-4-sulfônico (redutor), utilizado para eliminar a interferência do $\mathrm{P}$ e do $\mathrm{Fe}$, foi substituído pelo ácido oxálico $\left(75 \mathrm{~g}\right.$ de $(\mathrm{COOH})_{2} \cdot 2 \mathrm{H}_{2} \mathrm{O}$ em $200 \mathrm{~mL}$ de água destilada) na proporção de $2 \mathrm{~mL}$ por amostra. A leitura doSi nos extratos foi feita em fotocolorímetro, no comprimento de onda de $410 \mathrm{hm}$. A quantidade de Si acumulada na parte aérea (Quadro 1) foi calculada com base na concentração de Si ena produção de matéria seca da parte aérea.
Pretendeu-se, nesta partedotrabalho, quantificar - Si acumulado na parte aérea do arroz para servir de critério na avaliação dos métodos de extração os quais foram correlacionados com o Si acumulado.

\section{Estudo dos métodos de extração}

Para análise do Si, amostras de solo foram retiradas dos vasos cultivados com arroz de sequeiro e preparadas para análise. As amostras foram secas na temperatura ambiente (TFSA) e posteriormente peneiradas $(<2,0 \mathrm{~mm})$.

O procedimento de extração foi realizado procurando-se manter a mesma relação sol o:solução, isto é, para cada $10 \mathrm{~g}$ de solo, foram adicionados $100 \mathrm{~mL}$ de extrator. Os extratores utilizados foram: Ácido acético 0,5 mol L-1 (Snyder, 1991): $100 \mathrm{~mL}$ de ácido acético $0,5 \mathrm{~mol} \mathrm{~L}^{-1}$ foram adicionados em um frasco de plástico de $150 \mathrm{~mL}$ que continha $10 \mathrm{~g}$ de solo. O frasco de plástico foi tampado e agitado horizontal mente por uma hora. Passados 30 minutos, filtrou-se o extrato (funil de plástico), utilizando-se papel de filtro número 42; Tampão pH 4,0: $100 \mathrm{~mL}$ de uma sol ução tamponada a pH 4,0 deáci do acético mais acetato de sódio $(49,2 \mathrm{~mL}$ de ácido acético concentrado e 14,800 g de acetato de sódio anidro foram dissolvidos em 1 litro de água destilada e o pH ajustado para 4,0 com a adição de ácido acético) foram adicionados em um frasco plástico de $150 \mathrm{~mL}$ com $10 \mathrm{~g}$ de solo e agitados horizontalmente por uma hora. A seguir, mantiveram-se os frascos em repouso por 30 minutos e depois filtrou-se o extrato em funil de plástico e papel de filtro número 42; Cloreto de cál cio 0,0025 mol L-1 (Kilmer, 1965): $100 \mathrm{~mL}$ de uma solução de cloreto de cálcio $0,0025 \mathrm{~mol} \mathrm{~L}^{-1}$ foram adicionados em frasco de plástico com $10 \mathrm{~g}$ de solo. A seguir, agitou-se horizontal mente por 15 minutos e depois ficou decantando de um dia para o outro. No dia seguinte, os extratos foram filtrados (funil de plástico e papel de filtro número 42); Água: $100 \mathrm{~mL}$ deágua destilada e desmineralizada foram

Quadro 1. Atributos químicos e matéria orgânica referentes à camada de $0-20 \mathrm{~cm}$ das amostras de solo usadas no estudo

\begin{tabular}{|c|c|c|c|c|c|c|c|c|c|}
\hline Solo & $\mathrm{pH}-\mathrm{H}_{2} \mathrm{O}$ & $\mathbf{P}$ & $\mathbf{A l}^{3+}$ & $\mathrm{Ca}^{2+}$ & $\mathbf{S}$ & $\mathbf{T}$ & $\mathbf{v}$ & $\mathbf{m}$ & MO \\
\hline & & $\mathrm{mg} \mathrm{dm} \mathrm{m}^{-3}$ & 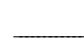 & $\mathrm{cm}$ & $n^{-3}$ & - & & & $\mathrm{g} \mathrm{kg}^{1}$ \\
\hline LVa & 5,0 & 4,0 & 0,70 & 0,20 & 0,29 & 7,70 & 4 & 70 & 45 \\
\hline LEa & 4,4 & 2,0 & 0,70 & 0,20 & 0,26 & 7,30 & 4 & 73 & 40 \\
\hline LRd & 5,0 & 16,0 & 0,50 & 3,80 & 5,80 & 11,8 & 49 & 8 & 41 \\
\hline AQa & 4,4 & 56,0 & 1,00 & 0,20 & 0,39 & 5,20 & 7 & 71 & 15 \\
\hline
\end{tabular}

Obs. $\mathrm{P}$ extraído com $\mathrm{HCl}$ 0,05 mol L-1 $+\mathrm{H}_{2} \mathrm{SO}_{4}$ 0,00125 mol L-1; $\mathrm{Al}$, Ca extraído com $\mathrm{KCl} 1 \mathrm{~mol} \mathrm{~L}^{-1}$; $\mathrm{S}=$ soma de bases; $\mathrm{T}=$ cap. troca de Cátion a pH 7.0; $\mathrm{V}$ = saturação por bases; $\mathrm{m}$ = saturação por alumínio; M.O. = matéria orgânica (EMBRAPA, 1979); Latossolo Vermelho-Amarelo álico (LVa), Latossolo Vermelho-Escuro álico (LEa), Latossolo Roxo distrófico (LRd) e Areia Quartzosa álica (AQa). 
Quadro 2. Elementos totais, índice de intemperismo ( $\mathrm{Ki})$, teores estimados de caulinita (Ka) e granulometria da terra fina referentes à camada de $0-20 \mathrm{~cm}$

\begin{tabular}{|c|c|c|c|c|c|c|c|c|c|}
\hline Solo $^{(1)}$ & $\mathrm{SiO}_{2}$ & $\mathrm{Al}_{2} \mathrm{O}_{3}$ & $\mathrm{Fe}_{2} \mathrm{O}_{3}$ & $\mathbf{K i}^{(2)} \mathrm{SiO}_{2} / \mathrm{Al}_{2} \mathrm{O}_{3}$ & $\mathbf{K a}$ & Areia grossa & Areia fina & Silte $^{(3)}$ & Argila \\
\hline & 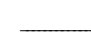 & $-\%$ & - & & & 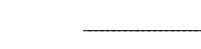 & $\%$ & 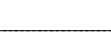 & - \\
\hline LVa & 13,5 & 29,6 & 7,8 & 0,77 & 29 & 6 & 10 & 10 & 74 \\
\hline LEa & 17,8 & 28,2 & 10,8 & 1,08 & 38 & 3 & 6 & 13 & 78 \\
\hline LRd & 12,2 & 11,9 & 18,9 & 1,75 & 26 & 6 & 22 & 20 & 52 \\
\hline AQa & 3,7 & 3,8 & 2,6 & 1,66 & 8 & 22 & 61 & 2 & 14 \\
\hline
\end{tabular}

(1) Elementos totais analisados pel o método do ataque sulfúrico (EMBRAPA, 1979). Latossolo Vermel ho-Amarel oálico (LVa), Latossolo Vermel ho-E scuroálico (LEa), Latossolo Roxo distrófico (LRd) eAreia Quartzosa álica (AQa). ${ }^{(2)}$ Relação molecular: \% $\mathrm{SiO}_{2} / \% \mathrm{Al}_{2} \mathrm{O}_{3} \times 1,7$.

(3) Análise textural, método da pipeta (EMBRAPA, 1979).

adicionados em frascos de plástico de $150 \mathrm{~mL}$ com $10 \mathrm{~g}$ de solo. Daí para frente, o procedimento foi 0 mesmo do ácido acético.

A determinação do Si no extrato foi feita misturando-se $10 \mathrm{~mL}$ do extrato (filtrado/decantado) com $1 \mathrm{~mL}$ da solução sulfo-molíbdica 7,5\% (7,5 g de molibdato deamônio $+10 \mathrm{~mL}$ deac. sulfúrico 9 mol L-1 em $100 \mathrm{~mL}$ ). A pós 10 minutos foram acrescentados $2 \mathrm{~mL}$ da solução ácido tartárico $20 \%$ e, após 5 minutos, adicionaram-se $10 \mathrm{~mL}$ da solução deácido ascórbico 0,3\%. Depois de uma hora, foi feita a leitura doSi em espectofotômetro eno comprimento deonda de $660 \mathrm{hm}$.

\section{RESULTADOS E DISCUSSÃO}

Relativamente pouca diferença existe entre os métodos de extração testados quanto à capacidade em estimar a disponibilidade do Si no solo para o arroz de sequeiro. Todos apresentaram el evado grau de correlação com o Si acumulado na parte aérea do arroz. Os coeficientes de determinação $\left(R^{2}\right)$ foram de 0,88; 0,84; 0,70 e 0,69, respectivamente, para os extratores ácido acético, água, cloreto de cálcio 0,0025 mol L-1 e tampão pH 4,0 (Figura 1).

O extrator queapresentou o maior coeficiente de determinação foi oáci do acético. Esse extrator, além de ser de simples preparo, também apresenta um custo de reagente bastante baixo e isso facilita seu uso em análises de rotina, isto é, para grandenúmero de amostras. Apesar de o coeficiente de determinação da água ter sido el evado $\left(R^{2}=0,84\right)$, esse extrator apresenta a inconveniência da dispersão que provoca nas partículas de argila, exigindo um tempo muito maior dedecantação, antes da filtragem. O áci do acético foi também o extrator que mais extraiu Si do solo (Quadro 3). Esse método extraiu 15, 108 e 108\% mais Si que os extratores tampão pH 4,0, cloreto de cálcio e água, respectivamente. A maior capacidade de extração do ácido acético pode, em parte, explicar o maior coeficiente de determinação, visto que quanto maior concentração de Si na solução menores erros de leitura. A água e o cloreto de cálcio foram os que menos extraíram Si. A extração com cl oreto de cál cio foi comparável com a água. Resultados semel hantes foram obtidos por Raij \& Camargo (1973).

O extrator tampão $\mathrm{pH} 4,0$ foi o que apresentou o menor coeficiente de determinação $\left(R^{2}=0,69\right)$ em relação ao Si acumulado pela planta, o que indica que, para os solos estudados, a liberação do Si da

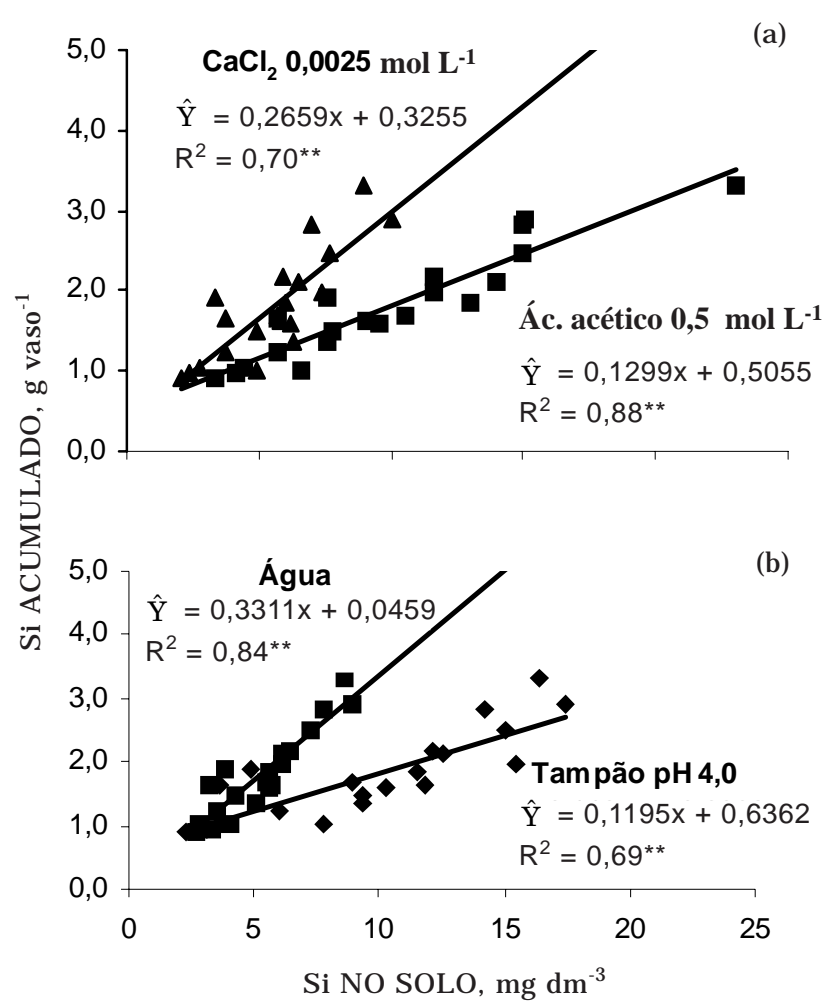

Figura 1. Relação entre o Si extraído pelos extratores ácido acético 0,5 mol L-1 e cloreto de cálcio (a) tampão pH 4,0 e água (b) e o Si acumulado na parte aérea de plantas de arroz de sequeiro. (** significativo a $1 \%$ ). 
Quadro 3. Silício extraído por quatro métodos em solos cultivados com arroz de sequeiro (tratamento com $960 \mathrm{~kg} \mathrm{ha}^{-1}$ de Si aplicado)

\begin{tabular}{|c|c|c|c|c|c|}
\hline \multirow{2}{*}{ Método de extração } & \multicolumn{4}{|c|}{ Solo } & \multirow{2}{*}{ Média } \\
\hline & LRd & LEa & LVa & AQa & \\
\hline & \multicolumn{5}{|c|}{$\mathrm{mg} \mathrm{dm}^{-3}$} \\
\hline Tampão pH 4,0 & 16,4 & 14,2 & 17,4 & 4,9 & 13,2 \\
\hline Ácido acético $0,5 \mathrm{~mol} \mathrm{~L}^{-1}$ & 23,0 & 15,0 & 15,1 & 7,6 & 15,2 \\
\hline Cloreto de cálcio $0,0025 \mathrm{~mol} \mathrm{~L}^{-1}$ & 9,0 & 7,0 & 10,0 & 3,3 & 7,3 \\
\hline Água & 8,6 & 7,8 & 8,9 & 3,8 & 7,3 \\
\hline
\end{tabular}

fase sólida para a solução é pouco dependente dos processos de adsorção ao contrário do que se imaginava. Segundo muitos autores (McKeague \& Cline, 1963; Miller, 1967; Brown \& Mahler, 1988), a adsorção do Si é dependente do $\mathrm{pH}$ e ocorre principalmente em condições de pH el evado. Como os solos estudados são de característica ácida (Quadro 1), isso explica a menor dependência dos processos de adsorção e a menor eficiência desse método em estimar a disponibilidade de Si para as plantas de arroz.

Partindo do princípio que o extrator ácido acético 0,5 mol L-1 é bom indicador do Si disponível no solo para a cultura do arroz de sequeiro, foi feito um estudo de regressão desse método com o teor de Si nas fol has dearroz. A figura 2 mostra oresultado desse estudo: foi encontrada uma relação positiva e altamente significativa do Si extraído pelo ácido acético e o teor de Si nas folhas $\left(R^{2}=0,89^{* *}\right)$. Além disso, foi feito um estudo dealgumas variáveis desse método, istoé, tempo de agitação e rel ação sol o:sol ução.

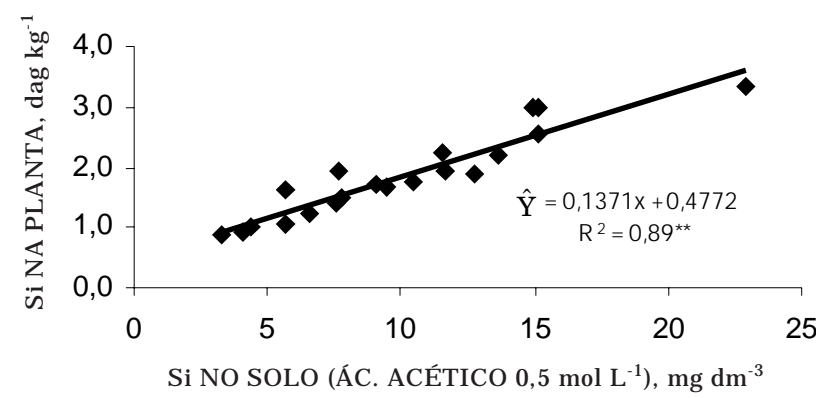

Figura 2. Teores deSi nas fol has do arroz de sequeiro em função do Si extraído do solo pelo método ácido acético 0,5 mol L-1. (** significativo a $1 \%$ ).

Examinando a influência do volume da solução extratora para determinado peso de solo, resultados obtidos a partir de 2 amostras fixas de cada solo (total $=8$ amostras), nota-se que o Si extraído diminuía quando se aumentava a relação solo:solução (Quadro 4). Valores de 18,1; 10,7 e $4,6 \mathrm{mg} \mathrm{dm}^{-3}$ foram obtidos (média dos quatro solos) para as relações solo:solução de 1:5; 1:10 e 1:25, respectivamente. I sso acontece porque o Si extraível não étotal mente removi do em uma ou mesmo várias extrações, pois os solos apresentam grande capacidade de restituir para a solução extratora o Si removido por extrações sucessivas. O tempo de agitação nao teve, aparentemente, influência na quantidade extraída de Si. Valores de 9,3; 7,6; 10,7 e $8,9 \mathrm{mg} \mathrm{dm}^{-3}$ (média de 8 amostras) foram obtidos para 5, 30, 60 e 90 minutos de agitação, respectivamente (Quadro 4).

Os mais altos valores de Si extraível (Quadro 3) foram observados no LRd (média dos quatro extratores testados). I sso indica que nesse solo há

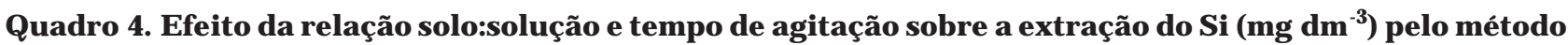
ácido acético 0,5 mol L-1

\begin{tabular}{|c|c|c|c|c|c|c|c|}
\hline \multirow{2}{*}{ Amostra de solo } & \multicolumn{3}{|c|}{ Relação sólido:solução } & \multicolumn{4}{|c|}{ Tempo de agitação } \\
\hline & 1:5 & 1:10 & $1: 25$ & $5^{\prime}$ & $30^{\prime}$ & $60^{\prime}$ & $90^{\prime}$ \\
\hline $\begin{array}{l}\mathrm{LVa}-0^{(1)} \\
\mathrm{LV} a-4^{(2)}\end{array}$ & $\begin{array}{l}10,7 \\
23,9\end{array}$ & $\begin{array}{r}5,4 \\
14,2\end{array}$ & $\begin{array}{l}2,7 \\
6,9\end{array}$ & $\begin{array}{r}3,3 \\
37,7\end{array}$ & $\begin{array}{r}2,9 \\
10,7\end{array}$ & $\begin{array}{r}5,4 \\
14,2\end{array}$ & $\begin{array}{r}2,7 \\
12,8\end{array}$ \\
\hline $\begin{array}{l}\text { LEa - } 0 \\
\text { LEa } 4\end{array}$ & $\begin{array}{l}10,2 \\
41,0\end{array}$ & $\begin{array}{r}6,7 \\
15,0\end{array}$ & $\begin{array}{l}2,7 \\
6,9\end{array}$ & $\begin{array}{l}5,6 \\
9,2\end{array}$ & $\begin{array}{r}6,7 \\
14,2\end{array}$ & $\begin{array}{r}6,7 \\
15,0\end{array}$ & $\begin{array}{r}4,8 \\
15,6\end{array}$ \\
\hline $\begin{array}{l}\text { LRd - } 0 \\
\text { LRd - } 4\end{array}$ & $\begin{array}{l}14,1 \\
27,8\end{array}$ & $\begin{array}{r}9,5 \\
24,5\end{array}$ & $\begin{array}{l}5,2 \\
7,4\end{array}$ & $\begin{array}{l}5,3 \\
7,8\end{array}$ & $\begin{array}{r}8,5 \\
14,2\end{array}$ & $\begin{array}{r}9,5 \\
24,4\end{array}$ & $\begin{array}{r}7,4 \\
16,4\end{array}$ \\
\hline $\begin{array}{l}\text { AQa - } 0 \\
\text { AQa- } 4\end{array}$ & $\begin{array}{r}4,1 \\
13,3\end{array}$ & $\begin{array}{l}2,7 \\
7,7\end{array}$ & $\begin{array}{l}1,9 \\
3,1\end{array}$ & $\begin{array}{l}1,7 \\
3,5\end{array}$ & $\begin{array}{l}1,3 \\
2,3\end{array}$ & $\begin{array}{l}2,7 \\
7,7\end{array}$ & $\begin{array}{l}2,8 \\
8,9\end{array}$ \\
\hline Médias & 18,1 & 10,7 & 4,6 & 9,3 & 7,6 & 10,7 & 8,9 \\
\hline
\end{tabular}

(1) Tratamento-testemunha. ${ }^{(2)} 960 \mathrm{~kg} \mathrm{ha}^{-1}$ de Si. 
menor chance de observar resposta à adubação com silício. A maior quantidade deSi extraível dessesolo está diretamente associada ao menor grau de intemperismo da fração argila (Quadro 2).

\section{CONCLUSÃO}

1. O áci do acético $0,5 \mathrm{~mol} \mathrm{~L}^{-1}$ foi o queapresentou a melhor estimativa do Si disponível no solo para o arroz de sequeiro.

\section{AGRADECIMENTOS}

Ao professor GilbertoF. Corrêa, da Universidade Federal de U berlândia, pelas idéias e sugestões; ao técnico de laboratório Paulo Rabelo, pelo auxílio nas análises de Si; à FUNDAÇÃO BANCO DO BRASIL eà FAPEMIG, pelo auxílio financeiro.

\section{LITERATURA CITADA}

ANDERSON, D.L.; SNYDER, G.H. \& MARTIN, F.G. Multi-year response of sugarcaneto calcium silicateslag on Everglades Histosols. Agron. J., 8:870-874, 1991.

BROWN, T.H. \& MAHLER, R.L. Relationships between soluble silica and plow pans in Palouse silt loam soils. Soil Sci., 145:359-364, 1988.

DATNOFF, L.E.; RAID, R.N.; SNYDER, G.H. \& J ONES, D.B. Effect of calcium silicate on blast and brown spot intensities and yields of rice. Plant Disease, 75:729-732, 1991.

ELLIOTT, C.L. \& SNYDER, G.H. Autoclave - induced digestion for the colorimetric determination of silicon in rice straw. J. Agric. Food. Chem., 39:1118-1119, 1991.
EMPRESA BRASILEIRA DE PESQUISA AGROPECUÁRIA EMBRAPA. Serviço Nacional de Levantamento e Conservação de Solos. Manual de Métodos de Análise de Solo. Rio de J aneiro, 1979. 80p.

EMPRESA BRASILEIRA DE PESQUISA AGROPECUÁRIA EMBRAPA. Serviço Nacional de Levantamento e Conservação de Sol os. Levantamento de média intensidade dos solos e avaliação da aptidão agrícola das terras do Triângulo Mineiro. Rio de J aneiro, 1982. 526p. (Boletim Técnico, 1)

FOX, R.L.; SILVA, J.; YOUNGE, R.; PLUCKNETT, D.L. \& SHERMAN, G.G. Soil and plant silicon and silicateresponse by sugar cane. Proc. Soil Sci. Soc. Am., 31:775-779, 1967.

GIBSON, J .A.E. Kinetics of silicon and aluminum release from soils during extration with 0,01 M calcium chloride. Comm. Soil Sci. Plant Anal., 25:3393-3403, 1994.

KILMER, V.J. Silicon. In: BLACK, C.A., ed. Methods of soil analysis. Madison, American Society of Agronomy, 1965 p.959-962. (Monograph 9)

McKEAGUE, J.A. \& CLINE, M.G. Silica in soil solution. II. The adsorption of monosilicic acid by soil and by other substances. Can. J. Soil Sci. 43:83-96, 1963.

MILLER, R.W. Solublesilica in soil. Proc. Soil Sci. Soc. Am., 31:4650, 1967.

NONAKA, K. \& TAKAHASHI, K. A method of assessing the need of silicate fertilizers in paddy soils. In: INTERNATIONAL CONGRESS SOIL SCIENCE, 14., Kioto, 1990. Proceedings. Kioto, 1990. 513-514.

RAIJ, B. van \& CAMARGO, A.O. Sílica disponível em solos. Bragantia, 32:223-236, 1973.

SHIUE, J J . The silicon content in soil of taiwan sugarcane fields. Rep. Taiwan Sug. Exp. Sta., 36:109-116, 1964.

SNYDER, G.H. Development of a silicon soil test for Histosolgrown rice. Belle Glade, Univ. Florida, 1991. (EREC Res. Report.) 